\title{
The Potential of Chitosan and Its Derivatives in Prevention and Treatment of Age-Related Diseases
}

\section{Garry Kerch}

Department of Materials Science and Applied Chemistry, Riga Technical University, Azenes 14/24, Riga, LV-1048, Latvia; E-Mail: garrykerch@inbox.lv; Tel.: +371-292-769-42

Academic Editor: Paola Laurienzo

Received: 19 February 2015 / Accepted: 26 March 2015 / Published: 13 April 2015

\begin{abstract}
Age-related, diet-related and protein conformational diseases, such as atherosclerosis, diabetes mellitus, cancer, hypercholesterolemia, cardiovascular and neurodegenerative diseases are common in the elderly population. The potential of chitosan, chitooligosaccharides and their derivatives in prevention and treatment of age-related dysfunctions is reviewed and discussed in this paper. The influence of oxidative stress, low density lipoprotein oxidation, increase of tissue stiffness, protein conformational changes, aging-associated chronic inflammation and their pathobiological significance have been considered. The chitosan-based functional food also has been reviewed.
\end{abstract}

Keywords: chitosan; chitooligosacharides; age-related diseases; protein conformations

\section{Introduction}

According to the recent report of The Department of Economic and Social Affairs of the United Nations Secretariat [1] globally, the number of elderly (aged 60 years or over) is expected to increase from 841 million people in 2013 to more than 2 billion in 2050. The global share of older persons increased from 9.2 per cent in 1990 to 11.7 per cent in 2013 and proportion of the world population will reach 21.1 per cent by 2050 . The share of older people aged 80 years or over (the "oldest old") within the older population (aged 60 years or over) was 14 per cent in 2013 and is expected to reach 19 percent in 2050 . There will be 392 million persons aged 80 years or over by 2050 . Women live longer than men, so the older population will be mainly female.

The quality of life depends on the nutrition of the elderly population [2,3]. World Health Organization devoted special attention to nutrition for older people. Degenerative age-related diseases 
such as cardiovascular and cerebrovascular disease, diabetes, osteoporosis and cancer are the common diseases in older persons, and these diseases are also diet-affected [4]. Elevated serum cholesterol, a risk factor for cardiovascular diseases, is common in older people. It has been estimated that a $10 \%$ reduction in blood cholesterol concentration can reduce the risk of coronary heart disease by $30 \%$. The decrease in salt and saturated fat intake can reduce blood pressure and blood cholesterol concentrations and can decrease the risk of cardiovascular disease. Increasing intake of fruit and vegetables by one to two servings daily could reduce cardiovascular risk by $30 \%$ [4].

Older people often suffer from impaired immunity [5-7]. Deficiency of trace elements zinc, iron, selenium, copper, Vitamins A, B, C, E have important impacts on immune responses. It has been reported [8] that chitooligosaccharide ascorbate is effective in compensation of deficiency in a number of minerals and vitamins. "The innate immune system is composed of a network of cells including neutrophils, NK and NKT cells, monocytes/macrophages, and dendritic cells that mediate the earliest interactions with pathogens. Age-associated defects are observed in the activation of all of these cell types, linked to compromised signal transduction pathways" [9]. Activation of intestinal T regulatory cells and homeostatic regulation of the gut microbiota may reduce low-grade inflammation in diet-related diseases [10] and, probably, also in age-related diseases.

Functional foods and nutraceuticals with antioxidant, anti-inflammatory, anti-diabetic and anticancer properties may prevent age-related and diet-related diseases. Decline in immune response with aging and the role of nutrition in enhancing immunity have been reviewed recently [11]. Dietary components have the potential to improve immunity in ageing. The molecular mechanism underlying effects of diet and functional food on immunity remain to be determined [12]. The herbal polysaccharides with antioxidant and anti-inflammatory properties that are able to inhibit protein aggregation and to prevent associated age-related diseases have been reviewed recently [13] as well as marine derived polysaccharides [14]. Chitosan is a linear natural nontoxic cationic polysaccharide that due to its biocompatibility, biodegradability and cationic nature has advantages in biomedical applications over other neutral or negatively charged polysaccharides. The properties and various applications of chitosan and its derivatives and composites have been described in a number of recent books [15-19]. The potential of chitosan and its derivatives to prevent age-related diseases is presented in Figure 1.

The structure, properties and applications of chitosan, chitooligosaccharides (COS) and their derivatives have been described in many review papers [20-30]. Chitosan is bioactive cationic polysaccharide with antibacterial, antifungal, antioxidant, antidiabetic, anti-inflammatory, anticancer, and hypocholesterolemic properties. Chitosan is used in biomedical and food applications. This review paper focuses on the ability of chitosan and COS to prevent age-related dysfunctions.

\section{Oxidative Stress}

Antioxidant effects of chitin, chitosan and their derivatives have been reviewed recently and it was concluded that their antioxidant properties play a vital role in human health and nutrition [31]. The studies on antioxidant properties that have not been included in this recent review are discussed here.

Increased risk of oxidative stress in elderly people has been reported [32]. Increased levels of reactive oxygen species (ROS) can cause oxidative modifications of lipids, proteins, and DNA. 
Oxidative stress and inflammation are involved in the pathology of age-related diseases such as cardiovascular diseases, cancer, neurodegenerative diseases, rheumatoid arthritis, and diabetes mellitus (Figure 1). It is important to protect the cells from oxidative damage by ROS [33-35].

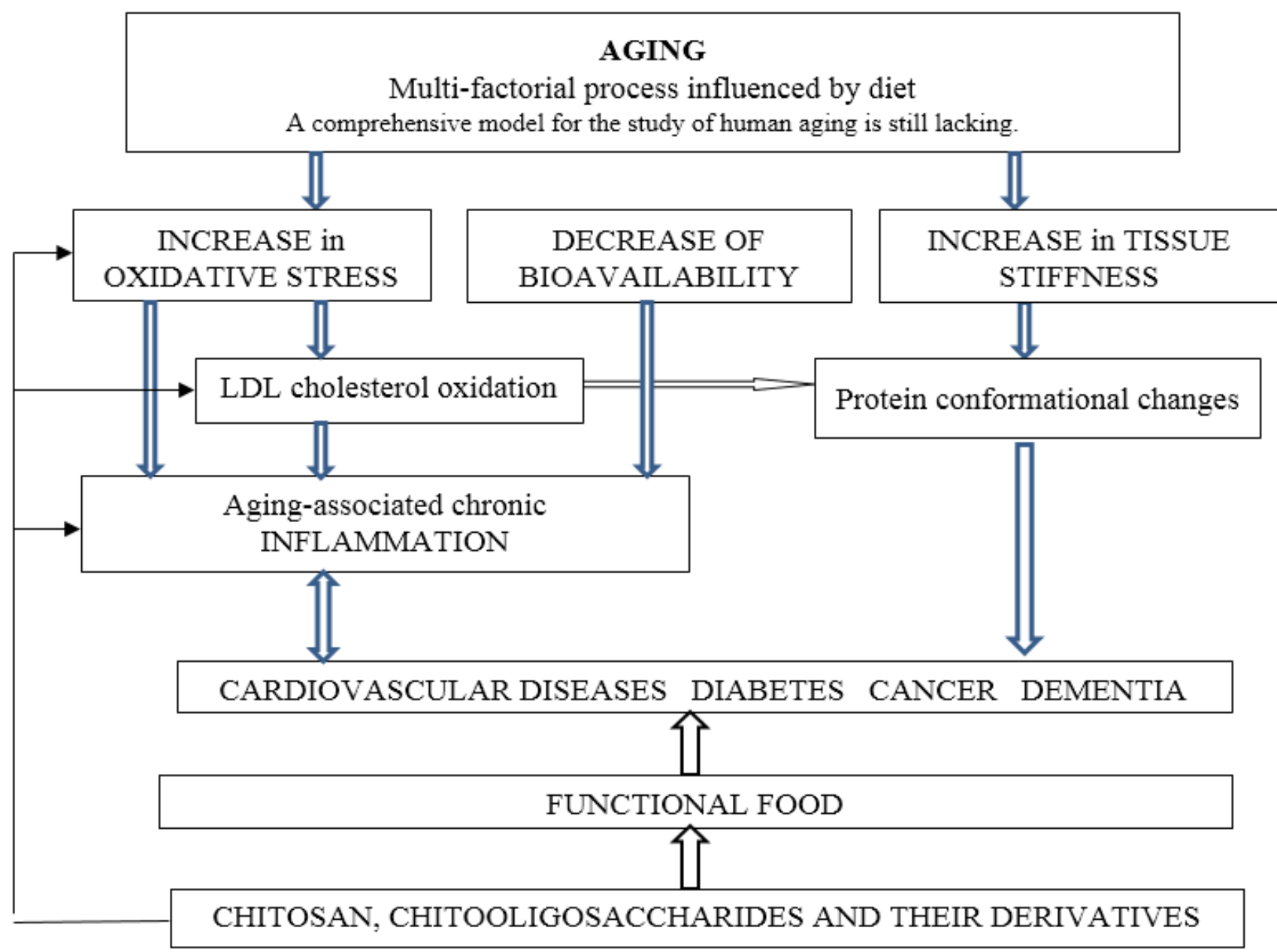

Figure 1. The potential effect of chitosan on age-related dysfunctions.

There is an urgent need to elucidate the role of oxidative stress in aging and to find promising perspectives on the efficacy of modulating agents for oxidative stress in treatment or prevention of age-related diseases. Perspectives on application of chitosan and its derivatives in the treatment of oxidative stress in age-related diseases have been considered in a number of research papers [31,36-46]. Researchers from Fukuyama University, Japan [43] concluded that chitosan has a direct antioxidant activity in systemic circulation by lowering the indices of oxidative stress in both in vitro and in vivo studies.

Researchers from Hubei University of Medicine, China, reported that COS inhibit ethanol-induced lipid peroxidation and glutathione depletion via the transcriptional activation of nuclear factor erythroid-2-related factor-2 (Nrf2) and reduction of the ethanol-induced phosphorylation of p38 MAPK, JNK and ERK [47]. Dietary chitosan supplementation attenuates isoprenaline-induced oxidative stress in rat myocardium [48] and the antiaging effect of dietary chitosan supplementation on glutathione-dependent antioxidant system in young and aged rats has been reported [49]. COS protect 
mice from oxidative stress [50]. Sulfated COS decrease intracellular ROS production. The researchers from Xi'an Jiaotong University, China [51] have reported protective effects of sulfated COS against hydrogen peroxide-induced damage in pancreatic $\beta$-cells MIN6. Sulfated COS significantly suppress nitric oxide (NO) production [52], the activity and mRNA expression of inducible NO synthase (iNOS), and the protein level of nuclear factor NF- $\kappa B$ protein p65 [52], which were activated by hydrogen peroxide $\mathrm{H}_{2} \mathrm{O}_{2}$. These results indicated the good anti-oxidative capacity of sulfated COS and the possible mechanism via the blockade of the nuclear factor NF- $\kappa B$ signaling pathway. The protective effects of sulfated COS against oxidative injuries in MIN6 cells depend both on their degree of substitution and concentration. The antioxidant action of low molecular weight chitosan was more effective in preventing the formation of carbonyl groups in plasma protein than high molecular weight chitosan [53]. The antioxidant activity of chitosan was increased after media milling. Rats fed media-milled chitosan showed increased superoxide dismutase activity [54]. Antioxidant activities of novel chitosan-caffeic acid, chitosan-ferulic acid, and chitosan-sinapic acid conjugates with different grafting ratios were investigated. The antioxidant activities of the conjugates were increased compared to the unmodified chitosan [55]. Researchers of Korea University, Seoul [56] reported that antioxidant property of chitosan green tea polyphenols complex induces transglutaminase activation in wound healing. Caffeic and ferulic acids were grafted onto chitosan by a free radical mediated method [57]. The novel compounds had improved peroxidation inhibition effects and increased free radical scavenging. The antioxidant activity of the phenol acids grafted $\mathrm{N}, \mathrm{O}$-carboxymethyl chitosan increased in order of chitosan $<$ N,O-carboxymethyl chitosan $<$ ferulic acid-N,O-carboxymethyl chitosan $<$ caffeic acid-N,O-carboxymethyl chitosan $<$ gallic acid-N,O-carboxymethyl chitosan [58]. COS reduce oxidative damage of DNA by inhibiting hydrogen peroxide $\mathrm{H}_{2} \mathrm{O}_{2}$ and AAPH radicals [59-63]

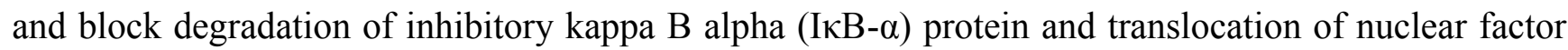

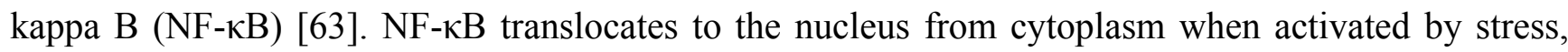
bacteria, inflammatory stimuli, cytokines, free radicals, carcinogens, and other agents. NF- $\kappa \mathrm{B}$ regulates the expression of enzymes (such as COX-2 and iNOS), cytokines (such as TNF, IL-1, IL-6, IL-8), adhesion molecules and has been linked with age-related diseases such as atherosclerosis, diabetes, osteoporosis, Alzheimer's disease, and cancer [64]. COS suppress NF- $\kappa$ B activation and so they are promising agents in prevention and treatment of age-related diseases.

The recent publications also show that grafting of natural antioxidant polyphenols on chitosan and COS derivatives, such as antioxidant sulfated COS [31], can result in the design of novel effective antioxidant nutraceuticals.

\section{Inflammation}

Oxidative stress and inflammation are involved in the pathology of age-related diseases such as cardiovascular diseases, cancer, neurodegenerative diseases, rheumatoid arthritis, and diabetes [33-35]. Chronic inflammation can be considered as a major risk factor for age-related diseases [65]. Oxidative stress results in upregulation of proinflammatory mediators (TNF- $\alpha$, IL-1 $\beta$, IL-6, COX-2, iNOS). Plasma TNF- $\alpha$ concentration is associated with aging and the risk of diabetes mellitus [66].

COS inhibit the expression of IL-6 in lipopolysaccharide (LPS)-induced human umbilical vein endothelial cells (HUVECs). The pre-treatment of HUVECs with COS inhibited the LPS-induced 
over-expression of phosphorylated p38 mitogen-activated protein kinase (MAPK), phosphorylated ERK1/2 and nuclear factor NF- $\kappa$ B. COS prevented degradation of inhibitory protein $\mathrm{I} \kappa \mathrm{B} \alpha$ in nuclear factor NF- $\mathrm{kB}$ and translocation of NF- $\mathrm{KB}$ from cytoplasm to nucleus [67].

COS inhibit LPS-induced over-expression of inflammatory cytokines IL-6 and TNF- $\alpha$ also in RAW264.7 macrophage cells through blockade of MAPK and PI3K/Akt signaling pathways and suppress the activation of NF- $\mathrm{BB}$ and activator protein-1 (AP-1) [68]. The similar behavior has been reported for sulfated COS [52]. It has been suggested recently [69] that COS block LPS-induced $O$-GlcNAcylation (a dynamic modification of proteins by $\beta$-linked $N$-acetylglucosamine) of NF- $\mathrm{B}$ and endothelial inflammatory response.

Adhesion molecules are involved in the adhesive interaction between endothelial cells and monocytes in inflammation. COS down regulate the expression of adhesion molecules E-selectin and ICAM-1 by inhibiting the phosphorylation of MAPKs and the activation of NF- $\kappa B$ in LPS-treated porcine iliac artery endothelial cells [70]. Sulfated chitosan inhibits P-selectin-mediated HL-60 leukocyte adhesion. Sulfochitosans exhibit inhibitory activity in the order: heparin $>N$-sulfated/6-O-sulfated chitosan $\geq 3-O, 6-O$-sulfated chitosan $>6-O$-sulfated chitosan $>>N$-sulfated chitosan. So, it can be concluded that the sulfation of the double site in chitosan is essential for efficient inhibition of P-selectin-mediated HL-60 leukocyte adhesion [71].

The effects of chitosan and quaternized chitosan on production of IL- $1 \beta$ and TNF- $\alpha$ in LPS-stimulated human periodontal ligament cells has been studied [72]. Chitosan inhibited the production of IL-1 $\beta$ and TNF- $\alpha$ and quaternized chitosan increased IL- $1 \beta$ and TNF- $\alpha$ production.

COS attenuate ocular inflammation in rats with experimental autoimmune anterior uveitis [73] and prevented retinal ischemia and reperfusion injury via reduced oxidative stress and inflammation [74].

The elevated plasma glucose, TNF- $\alpha$, and IL- 6 in diabetic rats were decreased after 10 weeks of chitosan feeding [75]. Biomarkers provide insights into complex disease mechanisms and can help to develop novel nutraceuticals. Evidently, it does not mean that it is enough to decrease the content of inflammatory biomarkers to completely prevent and treat diabetes and other age-related diseases.

COS inhibited the release and expression levels of inflammatory cytokines TNF- $\alpha$, IL- 6 and IL- $1 \beta$ in LPS-stimulated BV2 microglia. COS also attenuated the production of NO and prostaglandin E2 (PGE2) by inhibiting iNOS and cyclooxygenase-2 (COX-2) expressions [76]. It has been confirmed recently that COS decrease the levels of NO, TNF- $\alpha$ and IL- $1 \beta$, released from LPS-stimulated RAW264.7 cells by inhibiting the activation of the NF- $\kappa$ B pathway [77].

Chitosan decreased serum TNF- $\alpha$ and leptin levels in high fat fed rats [78]. NF- $\kappa$ B activation, and levels of TNF- $\alpha$ and IL-6 in colonic tissues, were suppressed in mice with inflammatory bowel disease receiving COS [79]. It has been reported that the oral intake of COS by elderly volunteers decreased inflammatory cytokines TNF- $\alpha$ and IL-1 $\beta$ levels [80]. COS added to diet have been reported as calcium fortifiers [81] in ovariectomised rats and this effect has been related to COS capacity to down-regulate mRNA and protein expression of COX-2, a key mediator linking inflammation and osteoporosis. It has been demonstrated in vivo that COS are able to induce an anti-inflammatory effect mediated by cyclooxygenase inhibition and reduction of prostaglandins [82].

The anti-inflammatory and anticancer properties of chitin oligosaccharide and chitosan oligosaccharide have been recently reviewed [83]. 


\section{Diabetes Mellitus}

Antidiabetic effects of chitin, chitosan and their derivatives have been reviewed recently [84]. It has been concluded that chitosan and its derivatives have the potential to be used in several antidiabetic therapeutic applications and future research should be directed to enhance the effectiveness of novel chitosan derivatives and chitosan-based compounds to be used as potent nutraceuticals for prevention of diabetes and diabetes-related complications. So, the studies on antidiabetic properties of chitosan, COS and their derivatives that have not been included in this recent review are discussed here with special attention given to application in age-related diabetes.

Protein-rich diet is recommended at present for the treatment of elderly malnutrition. However, it was demonstrated recently in a large population-based prospective study by scientists of Lund University [85] that high intakes of protein and processed meat are associated with increased incidence of type 2 diabetes. At the same time, the intake of fiber-rich bread and cereals was inversely associated with type 2 diabetes. Insulin independent diabetes mellitus, the type II diabetes, is a serious global problem getting worse every year. The team of researchers from University of Southern California led by Longo [86] also reported that high protein intake was associated with reduced cancer and overall mortality in respondents over 65 , but a five-fold increase in diabetes mortality across all ages. It must be also taken into account that diabetes mellitus is a risk factor for incidence of age-related dementia, Alzheimer's disease, and cardiovascular diseases. So, a novel, complex balanced, more safe protein-rich diet and functional food to tackle malnutrition in elderly with lower risk of diabetes development must be designed.

The use of antioxidants reduces oxidative stress and alleviates diabetic complications [87]. Oxidative stress common for older people can lead to increased lipid peroxidation and development of diabetes mellitus $[88,89]$. TNF- $\alpha$ expression in the insulin resistant subjects and the diabetic patients was four-fold higher than in the insulin sensitive subjects [90]. Plasma TNF- $\alpha$ concentration is significantly associated with advancing age and it predicts the impairment in insulin action with advancing age [66]. Miura and coworkers [91] reported that chitosan had blood glucose-lowering and lipid-lowering effects in neonatal streptozotocin-induced diabetic mice. Hayashi and Ito [92] reported that low molecular-weight chitosan lactate had an antidiabetic effect also in obese diabetic KK-Ay mice. Chitosan may possess a potential for alleviating type-1 diabetic hyperglycemia through the decrease in liver gluconeogenesis and increase in skeletal muscle glucose uptake and use [93]. A randomized, double-blind, placebo-controlled clinical trial on 12 week supplementation of COS in subjects with prediabetes showed a significant decrease in the serum glucose level [94]. The effects of chitosan-oligosaccharide (GO2KA1) on postprandial blood glucose levels in adults with normal blood glucose levels have been recently reported $[95,96]$. GO2KA1 reduced postprandial blood glucose level due to the decrease of absorption of glucose in the small intestine as a result of carbohydrate hydrolyzing enzyme inhibition. Hsieh and coworkers [75] demonstrated that chitosan reduces plasma adipocytokines and lipid accumulation in liver and adipose tissues and ameliorates insulin resistance in diabetic rats. After 10 weeks of feeding, the elevated plasma glucose, TNF- $\alpha$, and IL-6 and lower adiponectin levels caused by diabetes were effectively reversed by chitosan treatment. Chitosan feeding also reduced hepatic triglyceride and cholesterol contents. Hsieh and coworkers consider that 
long-term administration of chitosan may reduce insulin resistance through suppression of lipid accumulation in liver and adipose tissues and amelioration of chronic inflammation in diabetic rats.

\section{Hypercholesterolemia}

Low-density lipoprotein (LDL) oxidation is associated with coronary atherosclerosis. High levels of cholesterol oxidation products in oxidized LDL are toxic for endothelial cells [97,98]. Removal of oxidized LDL is an important part of the protective role of the macrophage in the inflammatory response [99]. Mediators of inflammation such as TNF- $\alpha$, IL-1, and macrophage colony-stimulating factor increase binding of LDL to endothelium and smooth muscle. Antioxidants have an anti-inflammatory effect by preventing the up-regulation of adhesion molecules for monocytes. Antioxidants increase the resistance of human LDL to oxidation. High-density lipoproteins inhibit cytokine-induced expression of endothelial cell adhesion molecules [100].

Hypocholesterolemic effects of chitosan have been reported in many publications [101-111]. Recently, it has been demonstrated that the effect of media-milled chitosan on the decrease of serum triacylglycerol, total cholesterol and LDL cholesterol is higher compared to chitosan [54]. It has been also demonstrated recently that total cholesterol content in mice blood fed during 12 weeks with $\gamma$-irradiated chitosan (30-100 kGy) was significantly lower than that of the control [112]. The role of chitosan in lipid lowering treatment has been discussed recently by Patti and coworkers [113].

\section{Cancer}

In a recent review [31], it has been concluded that formation of cancer cells can be induced by free radicals. Hence, antioxidant properties of chitosan and its derivatives can be used to reduce the chance for the formation of cancer in the human body.

The anticancer properties of chitin and chitosan oligosaccharides have been recently reviewed [83]. Chitin and chitosan oligosaccharides have been evaluated as functional foods against cancer. The studies on anticancer properties that have not been included in this recent review are discussed here.

Polyphenols, such as curcumin or resveratrol, are effective natural antioxidants and their bioavailability can be essentially improved by encapsulation in chitosan-based nanoparticles [114] to be delivered to cancer cells. It has been also reported that novel cationic curcumin-chitosan poly (butyl cyanoacrylate) nanoparticles synthesized by emulsion polymerization, can improve the bioavailability of hydrophobic drug curcumin, suppress hepatocellular carcinoma growth and inhibit tumor angiogenesis efficiently in vitro and in vivo [115]. Rejinold and coworkers [116] fabricated curcumin with biodegradable thermoresponsive chitosan-g-poly ( $N$-vinylcaprolactam) nanoparticles (TRC-NPs) for cancer drug delivery. Their results indicate that novel curcumin-loaded TRC-NPs could be a promising candidate for cancer drug delivery. The anticancer effect can be explained by activation of apoptosis signaling (curcumin inhibits Bcl2 and activates caspase 9 to induce apoptosis) and blockade of cell proliferation signaling pathways (such as MAP kinase pathway, AKT pathway and mTOR pathways) [117-121]. Researchers from Universidade Federal de Santa Catarina, Florianópolis, Brazil and Université Grenoble Alpes, Grenoble, France published a number of papers describing curcumin-loaded chitosan-coated nanoparticles. Curcumin-loaded chitosan-coated nanoparticles can be used for the local treatment of oral cavity cancer [122]. The mucoadhesive properties of chitosan due 
to its polycation nature have been used to prepare films containing chitosan-coated nanoparticles for buccal delivery of curcumin [123]. Xyloglucan-block-poly ( $€$-Caprolactone) copolymer nanoparticles coated with chitosan were developed as biocompatible mucoadhesive drug delivery system [124]. Chitosan interacts with mucin through electrostatic forces between protonated amino groups of chitosan and negatively charged groups of mucin [125].

It has been also reported that oral administration of chitosan based nanoformulated green tea polyphenol EGCG effectively inhibits prostate cancer cell growth [126]. EGCG has been encapsulated also into chitosan-coated nanoliposomes and anticancer effects are expected in the treatment of breast cancer [127].

The curcumin/5-fluorouracil loaded thiolated chitosan nanoparticles showed enhanced anticancer effects on colon cancer cells in vitro and improved the bioavailability of the drugs in vivo [128]. The 5-fluorouracil and curcumin released from the N,O-carboxymethyl chitosan nanoparticles also produced enhanced anticancer effects in vitro in colon cancer cells HT 29 and improved plasma concentrations under in vivo conditions in mouse model [129].

Chitosan-based nanoparticles for tumor-targeted drug delivery that display a range of useful properties such as biocompatibility, biodegradability, excellent cell membrane penetrability, high drug-carrying capacities, $\mathrm{pH}$-dependent unloading and prolonged circulating time have been recently reviewed by Prabaharan [130]. The possible anticancer effect of chitosan and polyphenols encapsulated in chitosan nanoparticles is presented in Figure 2.

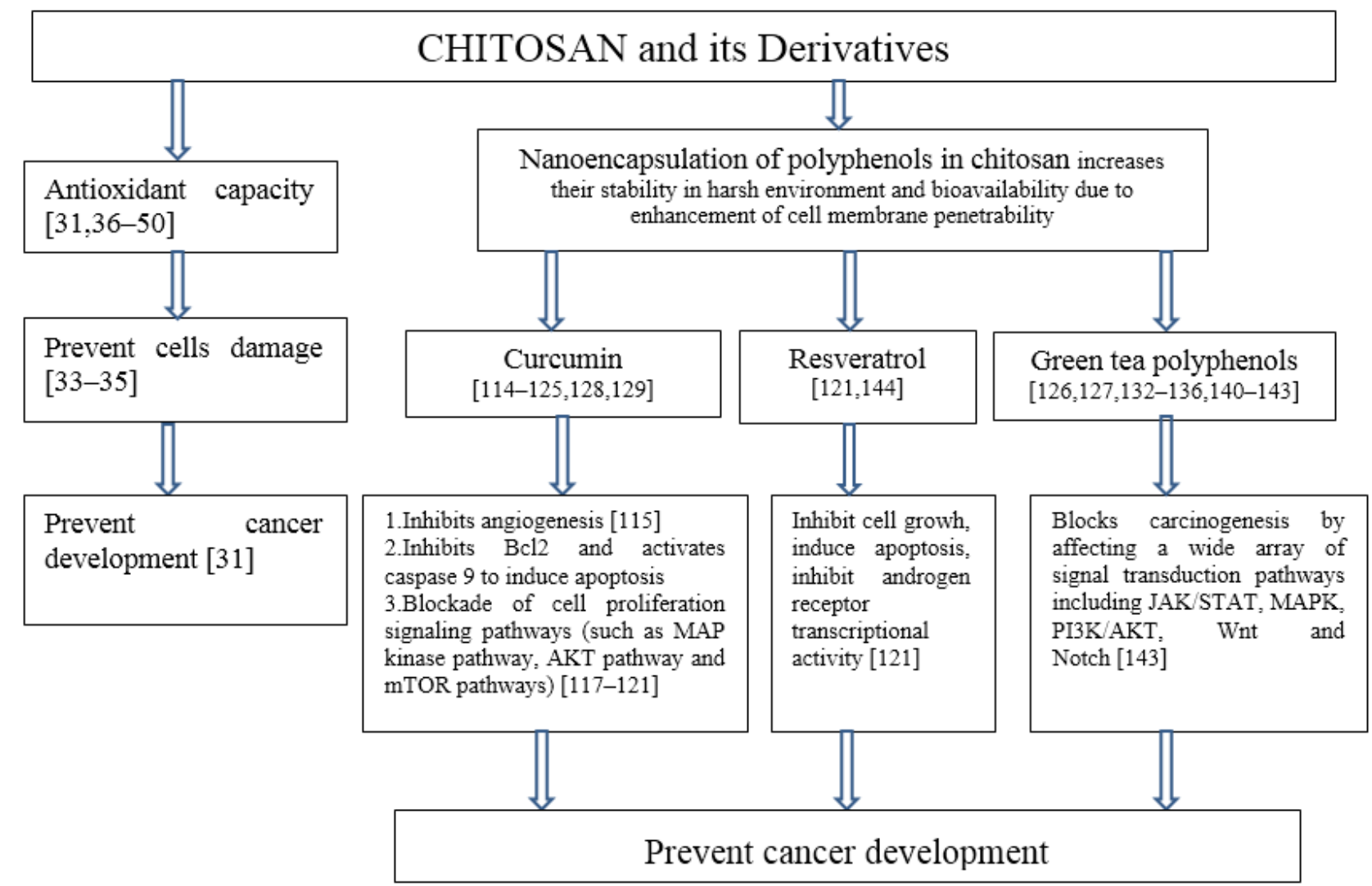

Figure 2. The possible anticancer effect of chitosan and polyphenols encapsulated in chitosan nanoparticles. 


\section{Nanomedicine}

Application of chitosan as drug carriers has been reviewed [130,131]. Decrease of bioavailability of nutrients with aging is an important problem leading to age-related dysfunctions. So, it is a great challenge to use chitosan as carriers of nutraceuticals that are able to delay or prevent age-related dysfunctions.

Catechins found in green tea have demonstrated antioxidant, cardioprotective, neuroprotective and anticancer effects. However, the oral administration of these oxidation-sensitive compounds is limited by the harsh environment of the gastrointestinal tract, their poor stability and intestinal absorption. Encapsulation in chitosan nanoparticles enhance the intestinal absorption of the green tea catechins $(+)$-catechin and (-)-epigallocatechin gallate (EGCG) [132]. Researchers from Monash University, Australia, considered that the mechanism by which absorption was enhanced was not through an effect of chitosan nanoparticles on intestinal paracellular or passive transcellular transport or an effect on efflux proteins but was likely due to stabilization of catechins after encapsulation. Oral absorption of encapsulated EGCG has been evaluated in Swiss Outbred mice. Administration of the chitosan nanoparticles enhanced the plasma exposure of total EGCG by a factor of 1.5 relative to an EGCG solution [133]. Nanochemoprevention by encapsulation of (-)-epigallocatechin-3-gallate with bioactive peptides/chitosan nanoparticles for enhancement of its bioavailability also has been reported [134].

Tang and coworkers [135] consider that chitosan nanoparticles with a positive surface charge could transiently open the tight junctions between Caco-2 cells and thus increase the paracellular transport of tea catechins. They prepared nanoparticles composed of chitosan and an edible polypeptide, poly ( $\gamma$-glutamic acid) $(\gamma$-PGA) for the delivery of tea catechins and demonstrated that chitosan/ $\gamma$-PGA nanoparticles can be effective as a carrier for oral delivery of tea catechins with effective antioxidant activity.

It must be taken into account $[136,137]$ that in comparison to the free-soluble polymers, the nanoparticles prepared by ionic gelation of the chitosan and its quaternized derivatives can have much lower effect on decreasing the transepithelial electrical resistance by opening of the tight junctions and on the permeability of cell layers in a Caco-2 cell system due to the reduced available amount of positive charge at the surface of the nanoparticles. However, no differences in cell permeability were detected between chitosan solution and chitosan nanoparticles on Calu-3 cells [138].

Chitosan coating prevents the aggregation of bovine serum albumin (BSA) - epigallocatechin gallate (EGCG) nanoparticles at pH 4.5-5.0 and may improve the absorption of EGCG [139]. Chitosan coating has been used also for (-)-epigallocatechin-3-gallate (EGCG) encapsulated nanostructured lipid carriers [140,141]. EGCG has been encapsulated into chitosan-coated nanoliposomes and a potential breakthrough in the prevention or even treatment of breast cancer has been expected [127]. Folate conjugated chitosan coated EGCG nanoparticles were prepared using the ionic gelation method with folic acid modified carboxymethyl chitosan and chitosan hydrochloride as carriers of catechin EGCG [142]. EGCG blocks carcinogenesis by affecting a wide array of signal transduction pathways including JAK/STAT, MAPK, PI3K/AKT, Wnt and Notch [143].

Chitosan/poly (D,L-lactic-co-glycolic acid) (PLGA) microcapsules were prepared by W/O/W double emulsion method and nutraceutical resveratrol was encapsulated into microcapsules [144]. 


\section{Neurodegenerative Diseases}

Cases of dementia and Alzheimer's are expected to almost double every 20 years to around 66 million in 2030 and over 115 million in 2050 [145].

A chronic inflammatory response associated with $A \beta$ and IL-1 $\beta$ is responsible for the pathology of Alzheimer's disease. The polyphenol EGCG binds directly to a large number of proteins that are involved in protein misfolding diseases and inhibits their fibrillization [146]. Water-soluble chitosan inhibits the production of pro-inflammatory cytokine in human astrocytoma cells activated by A $\beta$ and IL-1 $\beta$ and may reduce and delay the pathological events associated with Alzheimer's disease [147].

The effect of COS on NO production in LPS induced N9 microglial cells has been studied [148]. Pretreatment with COS could inhibit NO production by suppressing iNOS expression in activated microglial cells. COS inhibited LPS-induced phosphorylation of p38 MAPK and ERK1/2. COS pretreatment could also inhibit the activation of both NF- $\kappa \mathrm{B}$ and activator protein-1 (AP-1). The possible effect of chitosan oligosaccharide on Alzheimer disease pathology is presented in Figure 3.

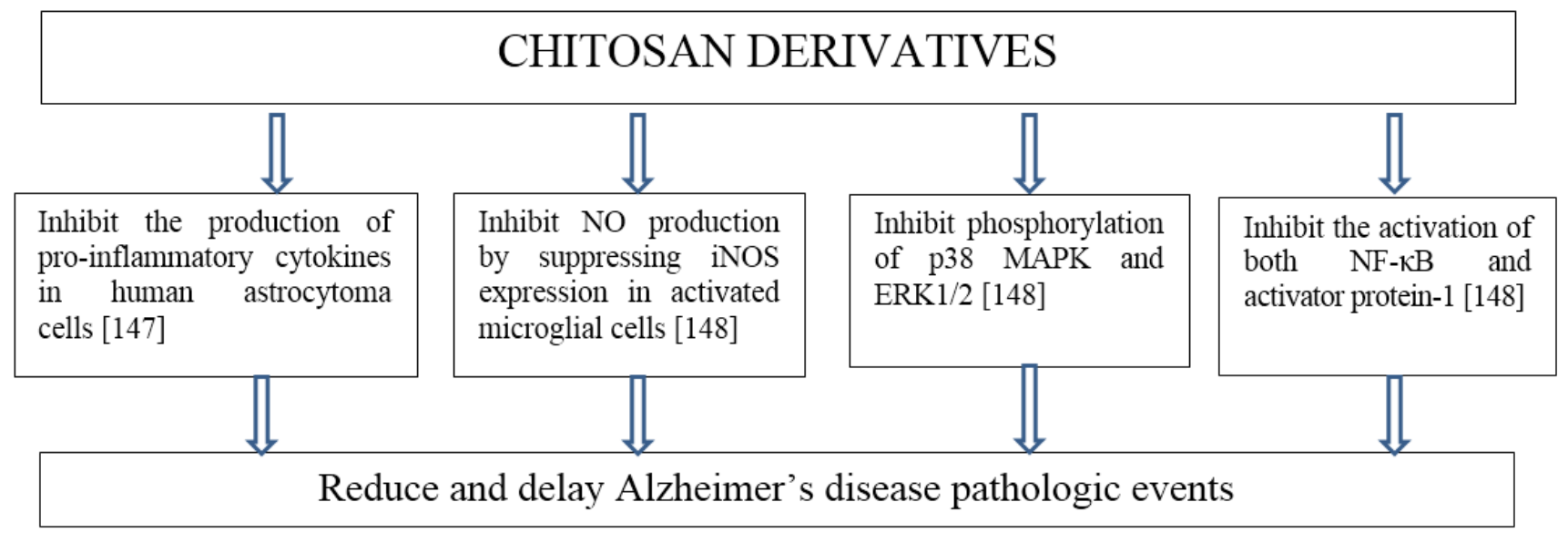

Figure 3. The possible effect of chitosan oligosaccharide on Alzheimer disease pathology.

\section{Protein Conformational Diseases}

The changes in protein conformations lead to protein conformational diseases that are also age-related diseases - diabetes mellitus, cataract, Alzheimer's disease, dementia, and atherosclerosis. Protein oxidation or glycation induces protein unfolding, adhesion of unfolded proteins to the arterial wall with increased arterial stiffness and the initiation of vascular inflammation and atherosclerosis [149-154]. Atherosclerotic plaques contain oxidized LDL which has amyloid properties [155] and activates platelets [151]. Misfolded proteins support platelet activation and aggregation leading to protein conformational diseases [156,157].

The presence of water at the protein-lipid interface of membrane proteins can affect the changes in protein conformations. Cholesterol is known to reduce the water content of lipid bilayers. Changes in the degree of hydration can lead to changes in protein conformation [158]. Chitosan prevents formation of carbonyl and hydroperoxide groups in human serum albumin exposed to peroxyl radicals and inhibits conformational changes in the protein, assessed by absorption spectrum and intrinsic fluorescence [159]. 
Proteins can be denatured by various stresses. Various additives are known to minimize the damage and to enhance the stability of proteins [160]. So, the possible mechanism of beneficial effect of COS in protein conformational diseases can be also due to their ability to prevent conformational changes in proteins. Tissue dehydration with aging [161] can cause protein conformational changes. The possible effect of chitosan on protein conformational diseases is presented in Figure 4. The need for further research in this area is evident.

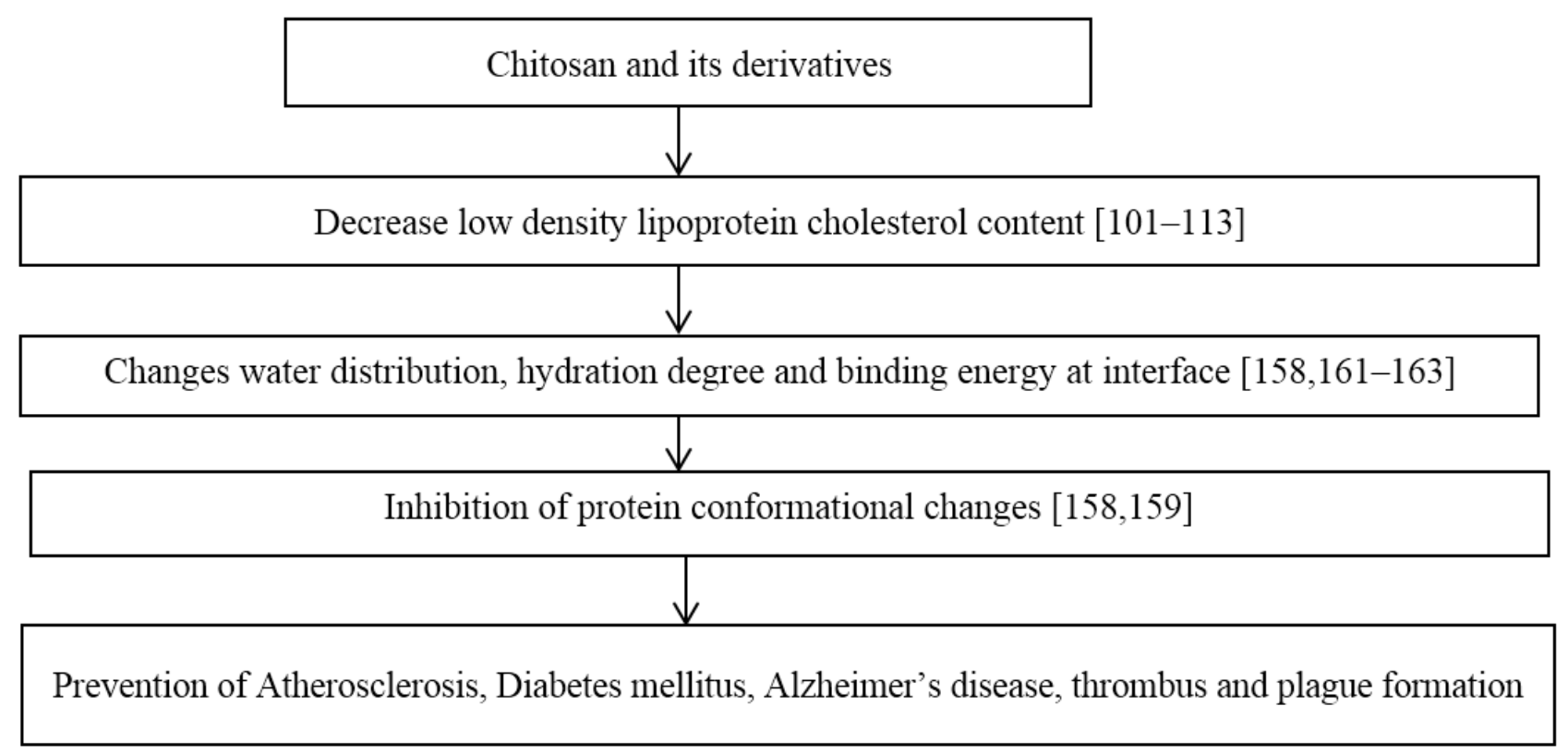

Figure 4. The possible influence of chitosan on low density lipoprotein cholesterol content, hydration, protein conformation, and protein conformational diseases.

It has been demonstrated that the presence of chitosan can change water migration and distribution in complex food systems such as bread [162] and can change interaction and water distribution between gluten and starch. Also, it has been shown that chitosan can prevent platelet adhesion to implants if water molecules are tightly bound to chitosan macromolecules and do not prevent platelet adhesion if water molecules at interface are free or loosely bound to the chitosan coated surface [163]. In both cases, interaction with protein depends on the water binding energy to chitosan macromolecules.

\section{Chitosan Containing Food}

It would be desirable if health promoting additives are used in everyday food and the elderly will not be forced to make drastic dietary changes. So, bread and dairy food containing chitosan and its derivatives could be the most appropriate functional food.

\subsection{Bread Containing Chitosan and Its Derivatives}

The papers published before 2007 have been reviewed by No et al. [164] and they reported that chitosan [165,166] and chitosan oligosaccharide [167] coatings extend shelf life of bread. The additives of chitosan [168] and carboxymethyl chitosan [169] also have been reported to extend shelf life of bread. The extension of bread shelf life has been explained by inhibiting microbial growth and 
by retarding starch retrogradation. Chitosans with higher molecular weight (30 and $120 \mathrm{kDa}$ ) have been reported to be more effective than chitosans with lower molecular weight (1 and $5 \mathrm{kDa})$ in extending the shelf life of bread.

The patients receiving chitosan-containing bread during 12 weeks decreased their mean levels of LDL-cholesterol and significantly increased their mean levels of HDL-cholesterol at the end of the study [101].

However, it has been also reported that chitosan increases the rate of bread staling [162]. Chitosan oligosaccharides and low molecular weight chitosan increase bread crumb staling rate to a much lesser extent than does middle molecular weight chitosan [170].

The addition of microcrystalline chitin increased specific loaf volume of white bread and protein fortified breads [171]. The properties of bread containing chitosan have been studied in a number of publications [172-177].

Chitosan has been approved as a food additive in Korea and Japan since 1995 and 1983, respectively. US FDA approved for chitosan GRAS status [154], so chitosan also can be used as a food additive.

\subsection{Dairy Products Containing Chitosan and Its Derivatives}

The use of chitosan in dairy products has been reported in a number of publications [164,178-190]. Microencapsulation with chitosan coating enhanced the survival of probiotic bacteria significantly in ice cream during storage compared to free cells [181]. Inhibitory effect of chitooligosaccharide on fermentation of sour cream [184] and inhibitory effect of chitosan on post-acidification of set yoghurt during cold storage [185] have been reported. Viscosity of sour cream increases with the increase of concentration of high molecular weight chitosan and anomalous viscosity decrease was observed with the increase in concentration of chitooligosaccharide [184].

\section{Conclusions and Perspectives}

Chitosan and COS due to their antioxidant, anti-inflammatory, antidiabetic, and anticancer properties show promising potential to be used in prevention, delay, mitigation and treatment of age-related dysfunctions and diseases. Hypocholesterolemic properties of chitosan decrease the risk of atherosclerosis and other cardiovascular dysfunctions common in elderly population. Chitosan ability to decrease serum total-cholesterol and LDL cholesterol levels, as well as to prevent their oxidation, changes water molecules distribution at biointerfaces and influences the conformation of proteins. So, chitosan has the potential to prevent protein conformational diseases that are also related with advanced aging. Mucoadhesive properties of chitosan can be applied in nanomedicine with potential to improve effectiveness of nutraceuticals and drug delivery systems. Combination of chitosan and COS with natural antioxidant polyphenols is promising. COS suppress nuclear factor NF- $\kappa \mathrm{B}$ activation and translocation of NF-kB from cytoplasm to nucleus that has been linked with a number of age-related diseases.

Development of novel COS derivatives such as sulfated, carboxylated and phenolic acid conjugated COS and their application in novel nanoparticulated systems, functional foods, and nutraceuticals can essentially increase bioavailability and stability of bioactive components. Mucoadhesive films 
containing chitosan-coated nanoparticles can find novel applications in nanomedicine. Breakthrough results in delay and prevention of age-related dysfunctions can be expected in the future.

\section{Acknowledgments}

This work stemmed from an initiative of the author, and was not financially supported.

\section{Conflicts of Interest}

The author declares no conflict of interest.

\section{References}

1. United Nations, Department of Economic and Social Affairs, Population Division. World Population Ageing 2013; ST/ESA/SER.A/348; United Nations: New York, NY, USA, 2013.

2. Brownie, S. Why are elderly individuals at risk of nutritional deficiency? Int. J. Nurs. Pract. 2006, 12, 110-118.

3. Wells, J.L.; Dumbrell, A.C. Nutrition and aging: assessment and treatment of compromised nutritional status in Frail elderly patients. Clin. Interv. Aging 2006, 1, 67-79.

4. World Health Organization Media centre. Available online: http://www.who.int/mediacentre/ factsheets/fs312/en/ (accessed on 16 November 2014).

5. Chandra, R.K. Nutrition and the immune system from birth to old age. Eur. J. Clin. Nutr. 2002, $56,73-76$.

6. Chandra, R.K. Nutrition and the immune system: An introduction. Am. J. Clin. Nutr. 1997, 66, 460-463.

7. Chandra, R.K. Nutrition, immunity and infection: From basic knowledge of dietary manipulation of immune responses to practical application of ameliorating suffering and improving survival. Proc. Natl. Acad. Sci. USA 1996, 93, 14304-14307.

8. Kirilenko, Y.K.; Dushkova, Z.G.; Cherkasova, E.I.; Sigilietov, A.E. Chitosan oligomer and ascorbic acid salt in compensation of deficiency of some micronutrients. In Advances in Chitin Science; Senel, S., Varum, K.M., Sumnu, M.M., Hincal, A.A., Eds.; TUBITAK: Antalya, Turkey, 2007; Volume 10.

9. Shaw, A.C.; Joshi, S.; Greenwood, H.; Panda, A.; Lord, J.M. Aging of the innate immune system. Curr. Opin. Immunol. 2010, 22, 507-513.

10. Magrone, T.; Perez de Heredia, F.; Jirillo, E.; Morabito, G.; Marcos, A.; Serafini, M. Functional foods and nutraceuticals as therapeutic tools for the treatment of diet-related diseases. Can. J. Physiol. Pharm. 2013, 91, 387-396.

11. Pae, M.; Meydani, S.N.; Wu, D. The role of nutrition in enhancing immunity in aging. Aging Dis. 2012, 3, 91-129.

12. Maijó, M.; Clements, S.J.; Ivory, K.; Nicoletti, C.; Carding, S.R. Nutrition, diet and immunosenescence. Mech. Ageing Dev. 2014, 136-137, 116-128. 
13. Li, H.; Ma, F.; Hu, M.; Ma, C.W.; Xiao, L.; Zhang, J.; Xiang, Y.; Huang, Z. Polysaccharides from medicinal herbs as potential therapeutics for aging and age-related neurodegeneration. Rejuvenation Res. 2014, 17, 201-204.

14. d'Ayala, G.G.; Malinconico, M.; Laurienzo, P. Marine derived polysaccharides for biomedical applications: Chemical modification approaches. Molecules 2008, 13, 2069-2106.

15. Chitin and Chitosan Derivatives: Advances in Drug Discovery and Developments; Kim, S.K., Ed.; CRC Press: Boca Raton, FL, USA, 2013; p. 527.

16. Chitosan-Based Hydrogels: Functions and Applications; Yao, K., Li, J., Yao, F., Yin, Y., Eds.; CRC Press: Boca Raton, FL, USA, 2011; p. 241.

17. Chitosan for Biomaterials I; Jayakumar, R., Prabaharan, M., Muzzarelli, R.A.A., Eds.; Springer: Berlin Heidelberg, Germany, 2011; p. 243.

18. Chitosan for Biomaterials II; Jayakumar, R., Prabaharan, M., Muzzarelli, R.A.A., Eds.; Springer: Berlin Heidelberg, Germany, 2011; p. 223.

19. Green Biorenewable Biocomposites: From Knowledge to Industrial Applications; Thakur, V.K., Kessler, M.R., Eds.; CRC Press: Boca Raton, USA, 2015; p. 568.

20. Xia, W.; Liu, P.; Zhang, J.; Chen, J. Biological activities of chitosan and chitooligosaccharides. Food Hydrocolloids 2011, 25, 170-179.

21. Kumar, M.N.V.R. A review of chitin and chitosan applications. React. Funct. Polym. 2000, 46, $1-27$.

22. Rinaudo, M. Chitin and chitosan: Properties and applications. Prog. Polym. Sci. 2006, 31, 603-632.

23. Kumar, M.N.V.R.; Muzzarelli, R.A.A.; Muzzarelli, C.; Sashiwa, H.; Domb, A.J. Chitosan chemistry and pharmaceutical perspectives. Chem. Rev. 2004, 104, 6017-6084.

24. Dash, M.; Chiellini, F.; Ottenbrite, R.M.; Chiellini, E. Chitosan-A versatile semi-synthetic polymer in biomedical applications. Prog. Polym. Sci. 2011, 36, 981-1014.

25. Anitha, A.; Sowmya, S.; Sudheesh Kumar, P.T.; Deepthi, S.; Chennazhi, K.P.; Ehrlich, H.; Tsurkan, M.; Jayakumar, R. Chitin and chitosan in selected biomedical applications. Prog. Polym. Sci. 2014, 39, 1644-1667.

26. Zhang, J.; Xia, W.; Liu, P.; Cheng, Q.; Tahi, T.; Gu, W.; Li, B. Chitosan modification and pharmaceutical/biomedical applications. Mar. Drugs 2010, 8, 1962-1987.

27. Jung, W.J.; Park, R.D. Bioproduction of chitooligosaccharides: Present and perspectives. Mar. Drugs 2014, 12, 5328-5356.

28. Muzzarelli, R.A.A.; El Mehtedi, M.; Mattioli-Belmonte, M. Emerging biomedical applications of nano-chitins and nano-chitosans obtained via advanced eco-friendly technologies from marine resources. Mar. Drugs 2014, 12, 5468-5502.

29. Laurienzo, P. Marine polysaccharides in pharmaceutical applications: An overview. Mar. Drugs 2010, 8, 2435-2465.

30. Thakur, V.K.; Thakur, M.K. Recent advances in graft copolymerization and applications of chitosan: A review. ACS Sustain. Chem. Eng. 2014, 2, 2637-2652.

31. Ngo, D.H.; Kim, S.K. Antioxidant effects of chitin, chitosan and their derivatives. In Marine Carbohydrates: Fundamentals and Applications, Part B; Kim, S.-K., Ed.; Elsevier Inc.: Oxford, UK, 2014; pp. 15-31. 
32. Andriollo-Sanchez, M.; Hininger-Favier, I.; Meunier, N.; Venneria, E.; O’Connor, J.M.; Maiani, G.; Coudray, C.; Roussel, A.M. Age-related oxidative stress and antioxidant parameters in middle-aged and older European subjects: The ZENITH study. Eur. J. Clin. Nutr. 2005, 59, 58-62.

33. Abdollahi, M.; Moridani, M.Y.; Aruoma, O.I.; Mostafalou, S. Oxidative stress in aging. Oxidative Med. Cell. Longev. 2014, 2014, 876834:1-876834:2.

34. Aruoma, O.I. Free radicals, oxidative stress, and antioxidants in human health and disease. J. Am. Oil Chem. Soc. 1998, 75, 199-212.

35. Saeidnia, S.; Abdollahi, M. Toxicological and pharmacological concerns on oxidative stress and related diseases. Toxicol. Appl. Pharm. 2013, 273, 442-455.

36. Xie, W.; Xu, P.; Liu, Q. Antioxidant activity of water-soluble chitosan derivatives. Bioorg. Med. Chem. Lett. 2001, 11, 1699-1701.

37. Jeon, T.I.; Hwang, S.G.; Park, N.G.; Jung, Y.R.; Shin, S.I.; Choi, S.D.; Park, D.K. Antioxidative effect of chitosan on chronic carbon tetrachloride induced hepatic injury in rats. Toxicology 2003, 187, 67-73.

38. Chen, A.S.; Taguchi, T.; Sakai, K.; Kikuchi, K.; Wang, M.W.; Miwa, I. Antioxidant activities of chitobiose and chitotriose. Biol. Pharm. Bull. 2003, 26, 1326-1330.

39. Sun, T.; Xie, W.; Xu, P. Superoxide anion scavenging activity of graft chitosan derivatives. Carbohydr. Polym. 2004, 58, 379-382.

40. Huang, R.; Mendis, E.; Kim, S.K. Factors affecting the free radical scavenging behavior of chitosan sulfate. Int. J. Biol. Macromol. 2005, 36, 120-127.

41. Feng, T.; Du, Y.; Li, J.; Wei, Y.; Yao, P. Antioxidant activity of half $N$-acetylated water-soluble chitosan in vitro. Eur. Food Res. Technol. 2007, 225, 133-138.

42. Yen, M.T.; Tseng, Y.H.; Li, R.C.; Mau, J.L. Antioxidant properties of fungal chitosan from shiitake stipes. LWT-Food Sci. Technol. 2007, 40, 255-261.

43. Anraku, M.; Fujii, T.; Furutani, N.; Kadowaki, D.; Maruyama, T.; Otagiri, M.; Gebicki, J.M.; Tomida, H. Antioxidant effects of a dietary supplement: Reduction of indices of oxidative stress in normal subjects by water-soluble chitosan. Food Chem, Toxicol. 2009, 47, 104-109.

44. Anraku, M.; Michihara, A.; Yasufuku, T.; Akasaki, K.; Tsuchiya, D.; Nishio, H.; Maruyama, T.; Otagiri, M.; Maezaki, Y.; Kondo, Y.; et al. The antioxidative and antilipidemic effects of different molecular weight chitosans in metabolic syndrome model rats. Biol. Pharm. Bull. 2010, 33, 1994-1998.

45. Friedman, M.; Juneja, V.K. Review of antimicrobial and antioxidative activities of chitosans in food. J. Food Prot. 2010, 73, 1737-1761.

46. Ngo, D.N. Chitin, Chitosan, and Their Derivatives against Oxidative Stress and Inflammation, and Some Applications. In Seafood Processing By-Products; Kim, S., Ed.; Springer: New York, NY, USA, 2014; pp. 389-405.

47. Luo, Z.; Dong, X.; Ke, Q.; Duan, Q.; Shen, L. Chitooligosaccharides inhibit ethanol-induced oxidative stress via activation of Nrf2 and reduction of MAPK phosphorylation. Oncol. Rep. 2014, 32, 2215-2222. 
48. Anandan, R.; Ganesan, B.; Obulesu, T.; Mathew, S.; Kumar, R.S.; Lakshmanan, P.T.; Zynudheen, A.A. Dietary chitosan supplementation attenuates isoprenaline-induced oxidative stress in rat myocardium. Int. J. Biol. Macromol. 2012, 51, 783-787.

49. Anandan, R.; Ganesan, B.; Obulesu, T.; Mathew, S.; Asha, K.K.; Lakshmanan, P.T.; Zynudheen, A.A. Antiaging effect of dietary chitosan supplementation on glutathione-dependent antioxidant system in young and aged rats. Cell Stress Chaperon 2013, 18, 121-125.

50. Qiao, Y.; Bai, X.F.; Du, Y.G. Chitosan oligosaccharides protect mice from LPS challenge by attenuation of inflammation and oxidative stress. Int. Immunopharmacol. 2011, 11, 121-127.

51. Lu, X.; Guo, H.; Sun, L.; Zhang, L.; Zhang, Y. Protective effects of sulfated chitooligosaccharides with different degrees of substitution in MIN6 cells. Int. J. Biol. Macromol. 2013, 52, 92-98.

52. Kim, J.H.; Kim, Y.S.; Hwang, J.W.; Han, Y.K.; Lee, J.S.; Kim, S.K.; Jeon, Y.J.; Moon, S.H.; Jeon, B.T.; Bahk, Y.Y.; et al. Sulfated chitosan oligosaccharides suppress LPS-induced NO production via JNK and NF-אB inactivation. Molecules 2014, 19, 18232-18247.

53. Tomida, H.; Fujii, T.; Furutani, N.; Michihara, A.; Yasufuku, T.; Akasaki, K.; Maruyama, T.; Otagiri, M.; Gebicki, J.M.; Anraku, M. Antioxidant properties of some different molecular weight chitosans. Carbohydr. Res. 2009, 344, 1690-1696.

54. Zhang, W.; Xia, W. Effect of media milling on lipid-lowering and antioxidant activities of chitosan. Int. J. Biol. Macromol. 2015, 72, 1402-1405.

55. Lee, D.S.; Woo, J.Y.; Ahn, C.B.; Je, J.Y. Chitosan-hydroxycinnamic acid conjugates: Preparation, antioxidant and antimicrobial activity. Food Chem. 2014, 148, 97-104.

56. Qin, Y.; Guo, X.W.; Li, L.; Wang, H.W.; Kim, W. The antioxidant property of chitosan green tea polyphenols complex induces transglutaminase activation in wound healing. J. Med. Food. 2013, 16, 487-498.

57. Liu, J.; Wen, X.; Lu, J.; Kan, J.; Jin, C. Free radical mediated grafting of chitosan with caffeic and ferulic acids: Structures and antioxidant activity. Int. J. Biol. Macromol. 2014, 65, 97-106.

58. Liu, J.; Lu, J.; Kan, J.; Tang, Y.; Jin, C. Preparation, characterization and antioxidant activity of phenolic acids grafted carboxymethyl chitosan. Int. J. Biol. Macromol. 2013, 62, 85-93.

59. Halder, S.K.; Jana, A.; Das, A.; Paul, T.; Mohapatra, P.K.D. Appraisal of antioxidant, anti-hemolytic and DNA shielding potentialities of chitosaccharides produced innovatively from shrimp shell by sequential treatment with immobilized enzymes. Food Chem. 2014, 158, 325-334.

60. Fernandes, J.C.; Eaton, P.; Nascimento, H.; Gião, M.S.; Ramos, Ó.S.; Belo, L.; Santos-Silva, A.; Pintado, M.E.; Malcata, F.X. Antioxidant activity of chitooligosaccharides upon two biological systems: Erythrocytes and bacteriophages. Carbohydr. Polym. 2010, 79, 1101-1106.

61. Ngo, D.N.; Kim, M.M.; Kim, S.K. Protective effects of aminoethyl-chitooligosaccharides against oxidative stress in mouse macrophage RAW 264.7 cells. Int. J. Biol. Macromol. 2012, 50, 624-631.

62. Prashanth, K.V.H.; Dharmesh, S.; Rao, K.S.J.; Tharanathan, R.N. Free radical-induced chitosan depolymerized products protect calf thymus DNA from oxidative damage. Carbohydr. Res. 2007, 342, 190-195.

63. Trinh, M.D.L.; Ngo, D.H.; Tran, D.K.; Tran, Q.T.; Vo, T.S.; Dinh, M.H.; Ngo, D.N. Prevention of $\mathrm{H}_{2} \mathrm{O}_{2}$-induced oxidative stress in Chang liver cells by 4-hydroxybenzyl-chitooligomers. Carbohydr. Polym. 2014, 103, 502-509. 
64. Ahn, K.S.; Aggarwal, B.B. Transcription factor NF-кB: A sensor for smoke and stress signals. Ann. N. Y. Acad. Sci. 2005, 1056, 218-233.

65. Chung, H.Y.; Cesari, M.; Anton, S.; Marzetti, E.; Giovannini, S.; Seo, A.Y.; Carter, C.; Yu, B.P.; Leeuwenburgh, C. Molecular inflammation: Underpinnings of aging and age-related diseases. Ageing Res. Rev. 2009, 8, 18-30.

66. Paolisso, G.; Rizzo, M.R.; Mazziotti, G.; Tagliamonte, M.R.; Gambardella, A.; Rotondi, M.; Carella, C.; Giugliano, D.; Varricchio, M.; D’Onofrio, F. Advancing age and insulin resistance: Role of plasma tumor necrosis factor-alpha. Am. J. Physiol. 1998, 275, E294-E299.

67. Liu, H.T.; Li, W.M.; Li, X.Y.; Xu, Q.S.; Liu, Q.S.; Bai, X.F.; Yu, C.; Du, Y.G. Chitosan oligosaccharides inhibit the expression of interleukin-6 in lipopolysaccharide-induced human umbilical vein endothelial cells through p38 and ERK1/2 protein kinases. Basic Clin. Pharmacol. Toxicol. 2010, 106, 362-371.

68. Ma, P.; Liu, H.T.; Wei, P.; Xu, Q.S.; Bai, X.F.; Du, Y.G.; Yu, C. Chitosan oligosaccharides inhibit LPS-induced over-expression of IL-6 and TNF- $\alpha$ in RAW264.7 macrophage cells through blockade of mitogen-activated protein kinase (MAPK) and PI3K/Akt signaling pathways. Carbohydr. Polym. 2011, 84, 1391-1398.

69. Li, Y.; Liu, H.; Xu, Q.S.; Du, Y.G.; Xu, J. Chitosan oligosaccharides block LPS-induced O-GlcNAcylation of NF- $\mathrm{kB}$ and endothelial inflammatory response. Carbohydr. Polym. 2014, 99, 568-578.

70. Li, Y.; Xu, Q.; Wei, P.; Cheng, L.; Peng, Q.; Li, S.; Yin, H.; Du, Y. Chitosan oligosaccharides downregulate the expression of E-selectin and ICAM-1 induced by LPS in endothelial cells by inhibiting MAP kinase signaling. Int. J. Mol. Med. 2014, 33, 392-400.

71. Huang, J.; Wang, R.; Liu, X.; Zeng, X.; Wei, M. Sulfochitosan inhibits P-selectin-mediated HL-60 leukocyte adhesion under flow conditions. Cell. Mol. Biol. Lett. 2013, 18, 200-208.

72. Ji, Q.; Deng, J.; Yu, X.; Xu, Q.; Wu, H.; Pan, J. Modulation of pro-inflammatory mediators in LPS-stimulated human periodontal ligament cells by chitosan and quaternized chitosan. Carbohydr. Polym. 2013, 92, 824-829.

73. Fang, I.M.; Yang, C.H.; Yang, C.M. Chitosan oligosaccharides attenuate ocular inflammation in rats with experimental autoimmune anterior uveitis. Mediat. Inflamm. 2014, 2014, 827847.

74. Fang, I.M.; Yang, C.M.; Yang, C.H. Chitosan oligosaccharides prevented retinal ischemia and reperfusion injury via reduced oxidative stress and inflammation in rats. Exp. Eye Res. 2015, 130, $38-50$.

75. Hsieh, Y.L.; Yao, H.T.; Cheng, R.S.; Chiang, M.T. Chitosan reduces plasma adipocytokines and lipid accumulation in liver and adipose tissues and ameliorates insulin resistance in diabetic rats. J. Med. Food 2012, 15, 453-460.

76. Pangestuti, R.; Bak, S.S.; Kim, S.K. Attenuation of pro-inflammatory mediators in LPS-stimulated BV2 microglia by chitooligosaccharides via the MAPK signaling pathway. Int. J. Biol. Macromol. 2011, 49, 599-606.

77. Zhu, J.; Zhang, Y.; Wu, G.; Xiao, Z.; Zhou, H.; Yu, X. Inhibitory effects of oligochitosan on TNF- $\alpha$, IL-1 $\beta$ and nitric oxide production in lipopolysaccharide-induced RAW264.7 cells. Mol. Med. Rep. 2015, 11, 729-733. 
78. Mohamed, M.M. Effects of chitosan and wheat bran on serum leptin, TNF- $\alpha$, lipid profile and oxidative status in animal model of non-alcoholic fatty liver. Aust. J. Basic Appl. Sci. 2011, 5, 1478-1488.

79. Yousef, M.; Pichyangkura, R.; Soodvilai, S.; Chatsudthipong, V.; Muanprasat, C. Chitosan oligosaccharide as potential therapy of inflammatory bowel disease: Therapeutic efficacy and possible mechanisms of action. Pharmacol. Res. 2012, 66, 66-79.

80. Kim, H.M.; Hong, S.H.; Yoo, S.J.; Baek, K.S.; Jeon, Y.J.; Choung, S.Y. Differential effects of chitooligosaccharides on serum cytokine levels in aged subjects. J. Med. Food 2006, 9, 427-430.

81. He, B.; Wang, J. Chitooligosaccharides prevent osteopenia by promoting bone formation and suppressing bone resorption in ovariectomised rats: Possible involvement of COX-2. Nat. Prod. Res. 2015, 29, 359-362.

82. Fernandes, J.; Spindola, H.; de Sousa, V.; Alice Santos-Silva, A.; Pintado, M.E.; Malcata, F.X.; Carvalho, J.E. Anti-inflammatory activity of chitooligosaccharides in Vivo. Mar. Drugs 2010, 8 , 1763-1768.

83. Azuma, K.; Osaki, T.; Minami, S.; Okamoto, Y. Anticancer and anti-inflammatory properties of chitin and chitosan oligosaccharides. J. Funct. Biomater. 2015, 6, 33-49.

84. Karadeniz, F.; Kim, S.K. Antidiabetic activities of chitosan and its derivatives: A mini review. In Marine Carbohydrates: Fundamentals and Applications, Part B; Kim, S., Ed.; Elsevier Inc.: Oxford, UK, 2014; pp. 15-31.

85. Ericson, U.; Sonestedt, E.; Gullberga, B.; Hellstrand, S.; Hindy, G.; Wirfält, E.; Orho-Melander, M. High intakes of protein and processed meat associate with increased incidence of type 2 diabetes. Br. J. Nutr. 2013, 109, 1143-1153.

86. Levine, M.E.; Suarez, J.A.; Brandhorst, S.; Balasubramanian, P.; Cheng, C.W.; Madia, F.; Fontana, L.; Mirisola, M.G.; Guevara-Aguirre, J.; Wan, J.; et al. Low protein intake is associated with a major reduction in IGF-1, cancer, and overall mortality in the 65 and younger but not older population. Cell Metab. 2014, 19, 407-417.

87. Rahimi, R.; Nikfar, S.; Larijani, B.; Abdollahi, M. A review on the role of antioxidants in the management of diabetes and its complications. Biomed. Pharmacother. 2005, 59, 365-373.

88. Maritim, A.C.; Sanders, R.A.; Watkins, J.B., III. Diabetes, oxidative stress, and antioxidants: A review. J. Biochem. Mol. Toxicol. 2003, 17, 24-38.

89. Giacco, F.; Brownlee, M. Oxidative stress and diabetic complications. Circ. Res. 2010, 107, 1058-1070.

90. Saghizadeh, M.; Ong, J.M.; Garvey, W.T.; Henry, R.R.; Kern, P.A. The expression of TNF alpha by human muscle. Relationship to insulin resistance. J. Clin. Investig. 1996, 97, 1111-1116.

91. Miura, T.; Usami, M.; Tsuura, Y.; Ishida, H.; Seino, Y. Hypoglycemic and hypolipidemic effect of chitosan in normal and neonatal streptozotocin-induced diabetic mice. Biol. Pharm. Bull. 1995, 18, 1623-1625.

92. Hayashi, K.; Ito, M. Antidiabetic action of low molecular weight chitosan in genetically obese diabetic KK-Ay mice. Biol. Pharm. Bull. 2002, 25, 188-192.

93. Liu, S.H.; Chang, Y.H.; Chiang, M.T. Chitosan reduces gluconeogenesis and increases glucose uptake in skeletal muscle in streptozotocin-induced diabetic rats. J. Agric. Food Chem. 2010, 58, 5795-5800. 
94. Kim, H.J.; Ahn, H.Y.; Kwak, J.H.; Shin, D.Y.; Kwon, Y.I.; Oh, C.G.; Lee, J.H. The effects of chitosan oligosaccharide (GO2KA1) supplementation on glucose control in subjects with prediabetes. Food Funct. 2014, 5, 2662-2669.

95. Jo, S.H.; Ha, K.S.; Lee, J.W.; Kim, Y.C.; Apostolidis, E.; Kwon, Y.I. The reduction effect of low molecular weight chitosan oligosaccharide (GO2KA1) on postprandial blood glucose levels in healthy individuals. Food Sci. Biotechnol. 2014, 23, 971-973.

96. Kim, J.G.; Jo, S.H.; Ha, K.S.; Kim, S.C.; Kim, Y.C.; Apostolidis, E.; Kwon, Y.I. Effect of long-term supplementation of low molecular weight chitosan oligosaccharide (GO2KA1) on fasting blood glucose and $\mathrm{HbAlc}$ in $\mathrm{db} / \mathrm{db}$ mice model and elucidation of mechanism of action. BMC Complement. Altern. Med. 2014, 14, 272.

97. Rong, J.X.; Rangaswamy, S.; Shen, S.; Dave, R.; Chang, Y.H.; Peterson, H.; Hodis, H.N.; Chisolm, G.M.; Sevanian, A. Arterial injury by cholesterol oxidation products causes endothelial dysfunction and arterial wall cholesterol accumulation. Arterioscl. Throm. Vas. 1998, 18, 1885-1894.

98. Sevanian, A.; Hodis, H.N.; Hwang, J.; McLeod, L.L.; Peterson, H. Characterization of endothelial cell injury by cholesterol oxidation products found in oxidized LDL. J. Lipid Res. 1995, 36, 1971-1986.

99. Ross, R. Atherosclerosis-An inflammatory disease. N. Engl. J. Med. 1999, 340, 115-149.

100. Cockerill, G.W.; Rye, K.A.; Gamble, J.R.; Vadas, M.A.; Barter, P.J. High-density lipoproteins inhibit cytokine-induced expression of endothelial cell adhesion molecules. Arterioscler. Thromb. Vasc. Biol. 1995, 15, 1987-1994.

101. Ausar, S.F.; Morcillo, M.; León, A.E.; Ribotta, P.D.; Masih, R.; Vilaro Mainero, M.; Amigone, J.L.; Rubin, G.; Lescano, C.; Castagna, L.F.; et al. Improvement of HDL- and LDL-cholesterol levels in diabetic subjects by feeding bread containing chitosan. J. Med. Food 2003, 6, 397-399.

102. Wuolijoki, E.; Hirvela, T.; Ylitalo, P. Decrease in serum LDL cholesterol with microcrystalline chitosan. Methods Find. Exp. Clin. Pharmacol. 1999, 21, 357-361.

103. Tai, T.S.; Sheu, W.H.H.; Lee, W.J.; Yao, H.T.; Chiang, M.T. Effect of chitosan on plasma lipoprotein concentrations in type 2 diabetic subjects with hypercholesterolemia. Diabetes Care 2000, 23, 1703-1704.

104. Kanauchi, O.; Deuchi, K.; Imasato, Y.; Shizukuishi, M.; Kobayashi, E. Mechanism for the inhibition of fat digestion by chitosan and for the synergistic effect of ascorbate. Biosci. Biotechnol. Biochem. 1995, 59, 786-790.

105. Rizzo, M.; Giglio, R.V.; Nikolic, D.; Patti, A.M.; Campanella, C.; Cocchi, M.; Katsiki, N.; Montalto, G. Effects of chitosan on plasma lipids and lipoproteins: A 4-month prospective pilot study. Angiology 2013, 65, 538-542.

106. Liu, J.; Zhang, J.; Xia, W. Hypocholesterolaemic effects of different chitosan samples in vitro and in vivo. Food Chem. 2008, 107, 419-425.

107. Choi, C.R.; Kim, E.K.; Kim, Y.S.; Je, J.Y.; An, S.H.; Lee, J.D.; Wang, J.H.; Ki, S.S.; Jeon, B.T.; Moon, S.H.; et al. Chitooligosaccharides decreases plasma lipid levels in healthy men. Int. J. Food Sci. Nutr. 2012, 63, 103-106.

108. Park, J.H.; Hong, E.K.; Ahn, J.; Kwak, H.S. Properties of nanopowdered chitosan and its cholesterol lowering effect in rats. Food Sci. Biotechnol. 2010, 19, 1457-1462. 
109. Chiang, M.T.; Yao, H.T.; Chen, H.C. Effect of dietary chitosans with different viscosity on plasma lipids and lipid peroxidation in rats fed on a diet enriched with cholesterol. Biosci. Biotechnol. Biochem. 2000, 64, 965-971.

110. Bokura, H.; Kobayashi, S. Chitosan decreases total cholesterol in women: A randomized, double-blind, placebo-controlled trial. Eur. J. Clin. Nutr. 2003, 57, 721-725.

111. Zhang, J.; Zhang, W.; Mamadouba, B.; Xia, W. A comparative study on hypolipidemic activities of high and low molecular weight chitosan in rats. Int. J. Biol. Macromol. 2012, 51, 504-508.

112. Rashid, T.U.; Shamsuddin, S.M.; Khan, M.A.; Rahman, M.M. Evaluation of Fat Binding Capacity of Gamma Irradiated Chitosan Extracted from Prawn Shell. Soft Mater. 2014, 12, 262-267.

113. Patti, A.M.; Katsiki, N.; Nikolic, D.; Al-Rasadi, K.; Rizzo, M. Nutraceuticals in lipid-lowering treatment a narrative review on the role of chitosan. Angiology 2014, doi:10.1177/ 0003319714542999.

114. Das, R.K.; Kasoju, N.; Bora, U. Encapsulation of curcumin in alginate-chitosan-pluronic composite nanoparticles for delivery to cancer cells. Nanomedicine 2010, 6, 153-160.

115. Duan, J.; Zhang, Y.; Han, S.; Chen, Y.; Li, B.; Liao, M.; Chen, W.; Deng, X.; Zhao, J.; Huang, B. Synthesis and in vitro/in vivo anti-cancer evaluation of curcumin-loaded chitosan/poly(butyl cyanoacrylate) nanoparticles. Int. J. Pharm. 2010, 400, 211-220.

116. Rejinold, N.S.; Muthunarayanan, M.; Divyarani, V.V.; Sreerekha, P.R.; Chennazhi, K.P.; Nair, S.V.; Tamura, H.; Jayakumar, R. Curcumin-loaded biocompatible thermoresponsive polymeric nanoparticles for cancer drug delivery. J. Colloid Interface Sci. 2011 360, 39-51.

117. Zaki, N. Progress and problems in nutraceuticals delivery. J. Bioequivalence Bioavailab. 2014, 6 , $75-77$.

118. Tang, H.; Murphy, C.J.; Zhang, B.; Shen, Y.; van Kirk, E.A.; Murdoch,W.J.; Radosz, M. Curcumin polymers as anticancer conjugates. Biomaterials 2010, 31, 7139-7149.

119. Shaikh, J.; Ankola, D.D.; Beniwal, V.; Singh, D.; Kumar, M.N. Nanoparticle encapsulation improves oral bioavailability of curcumin by at least 9-fold when compared to curcumin administered with piperine as absorption enhancer. Eur. J. Pharm. Sci. 2009, 37, 223-230.

120. Prajakta, D.; Ratnesh, J.; Chandan, K.; Suresh, S.; Grace, S.; Meera, V.; Vandana, P. Curcumin loaded $\mathrm{pH}$-sensitive nanoparticles for the treatment of colon cancer. J. Biomed. Nanotechnol. 2009, 5, 445-455.

121. Narayanan, N.K.; Nargi, D.; Randolph, C.; Narayanan, B.A. Liposome encapsulation of curcumin and resveratrol in combination reduces prostate cancer incidence in PTEN knockout mice. Int. J. Cancer 2009, 125, 1-8.

122. Mazzarino, L.; Loch-Neckel, G.; Bubniak, L.D.S.; Mazzucco, S.; Santos-Silva, M.C.; Borsali, R.; Lemos-Senna, E. Curcumin-loaded chitosan-coated nanoparticles as a new approach for the local treatment of oral cavity cancer. J. Nanosci. Nanotechnol. 2015, 15, 781-791.

123. Mazzarino, L.; Borsali, R.; Lemos-Senna, E. Mucoadhesive films containing chitosan-coated nanoparticles: A new strategy for buccal curcumin release. J. Pharm. Sci. 2014, 103, 3764-3771.

124. Mazzarino, L.; Otsuka, I.; Halila, S.; Bubniak Ldos, S.; Mazzucco, S.; Santos-Silva, M.C.; Lemos-Senna, E.; Borsali, R. Xyloglucan-block-Poly( $\epsilon$-Caprolactone) Copolymer Nanoparticles Coated with Chitosan as Biocompatible Mucoadhesive Drug Delivery System. Macromol. Biosci. 2014, 14, 709-719. 
125. Mazzarino, L.; Coche-Guérente, L.; Lemos-Senna, E.; Borsali, R. On the mucoadhesive properties of chitosan-coated polycaprolactone nanoparticles loaded with curcumin using quartz crystal microbalance with dissipation monitoring. J. Biomed. Nanotechnol. 2014, 10, 787-794.

126. Khan, N.; Adhami, V.M.; Siddiqui, I.A.; Bharali, D.J.; Mousa, S.A.; Mukhtar, H. Abstract 5438: Oral administration of naturally occurring chitosan based nanoformulated green tea polyphenol EGCG effectively inhibits prostate cancer cell growth in a xenograft model. In Proceedings of the 103rd Annual Meeting of the American Association for Cancer Research, Chicago, IL, USA, 31 March-4 April 2012; AACR: Philadelphia, PA, USA, 2012.

127. De Pace, R.C.; Liu, X.; Sun, M.; Nie, S.; Zhang, J.; Cai, Q.; Gao, W.; Pan, X.; Fan, Z.; Wang, S.; et al. Anticancer activities of (-)-epigallocatechin-3-gallate encapsulated nanoliposomes in MCF7 breast cancer cells. J. Liposome Res. 2013, 23, 187-196.

128. Anitha, A.; Deepa, N.; Chennazhi, K.P.; Lakshmanan, V.K.; Jayakumar, R. Combinatorial anticancer effects of curcumin and 5-fluorouracil loaded thiolated chitosan nanoparticles towards colon cancer treatment. Biochim. Biophys. Acta (BBA)—Gen. Subj. 2014, 1840, 2730-2743.

129. Anitha, A.; Sreeranganathan, M.; Chennazhi, K.P.; Lakshmanan, V.K.; Jayakumar, R. In vitro combinatorial anticancer effects of 5-fluorouracil and curcumin loaded N,O-carboxymethyl chitosan nanoparticles toward colon cancer and in vivo pharmacokinetic studies. Eur. J. Pharm. Biopharm. 2014, 88, 238-251.

130. Prabaharan, M. Chitosan-based nanoparticles for tumor-targeted drug delivery. Int. J. Biol. Macromol. 2015, 72, 1313-1322.

131. Wang, J.J.; Zeng, Z.W.; Xiao, R.Z.; T Xie, T.; Zhou, G.L.; Zhan, X.R.; Wang, S.L. Recent advances of chitosan nanoparticles as drug carriers. Int. J. Nanomed. 2011, 6, 765-774.

132. Dube, A.; Nicolazzo, J.A.; Larson, I. Chitosan nanoparticles enhance the intestinal absorption of the green tea catechins $(+)$-catechin and (-)-epigallocatechin gallate. Eur. J. Pharm. Sci. 2010, 41, 219-225.

133. Dube, A.; Nicolazzo, J.A.; Larson, I. Chitosan nanoparticles enhance the plasma exposure of (-)-epigallocatechin gallate in mice through an enhancement in intestinal stability. Eur. J. Pharm. Sci. 2011, 44, 422-426.

134. Hu, B.; Ting, Y.; Yang, X.; Tang, W.; Zeng, X.; Huang, Q. Nanochemoprevention by encapsulation of (-)-epigallocatechin-3-gallate with bioactive peptides/chitosan nanoparticles for enhancement of its bioavailability. Chem. Commun. 2012, 48, 2421-2423.

135. Tang, D.W.; Yu, S.H.; Ho, Y.C.; Huang, B.Q.; Tsai, G.J.; Hsieh, H.Y.; Sung, H.W.; Mi, F.L. Characterization of tea catechins-loaded nanoparticles prepared from chitosan and an edible polypeptide. Food Hydrocolloids 2013, 30, 33-41.

136. Oehlke, K.; Adamiuk, M.; Behsnilian, B.; Gräf, V.; Mayer-Miebach, E.; Walz, E.; Greine, R. Potential bioavailability enhancement of bioactive compounds using food-grade engineered nanomaterials: A review of the existing evidence. Food Funct. 2014, 5, 1341-1359.

137. Sadeghi, A.M.; Dorkoosh, F.A.; Avadi, M.R.; Weinhold, M.; Bayat, A.; Delie, F.; Gurny, R.; Larijani, B.; Rafiee-Tehrani, M.; Junginger, H.E. Permeation enhancer effect of chitosan and chitosan derivatives: Comparison of formulations as soluble polymers and nanoparticulate systems on insulin absorption in Caco-2 cells. Eur. J. Pharm. Biopharm. 2008, 70, 270-278. 
138. Vllasaliu, D.; Exposito-Harris, R.; Heras, A.; Casettari, L.; Garnett, M.; Illum, L.; Stolnik, S. Tight junction modulation by chitosan nanoparticles: Comparison with chitosan solution. Int. J. Pharm. 2010, 400, 183-193.

139. Li, Z.; Ha, J.; Zou, T.; Gu, L. Fabrication of coated bovine serum albumin (BSA)-epigallocatechin gallate (EGCG) nanoparticles and their transport across monolayers of human intestinal epithelial Caco-2 cells. Food Funct. 2014, 5, 1278-1285.

140. Zhang, J.; Nie, S.; Wang, S. Nanoencapsulation Enhances Epigallocatechin-3-gallate Stability and Its Antiatherogenic Bioactivities in Macrophages. J. Agric. Food Chem. 2013, 61, 9200-9209.

141. Hong, Z.; Xu, Y.Q.; Yin, J.F.; Jin, J.; Du, Q. Improving the Effectiveness of (-)-Epigallocatechin Gallate (EGCG) against Rabbit Atherosclerosis by EGCG-Loaded Nanoparticles Prepared from Chitosan and Polyaspartic Acid. J. Agric. Food Chem. 2014, 62, 12603-12609.

142. Liang, J.; Cao, L.; Zhang, L.; Wan, X.C. Preparation, characterization, and in vitro antitumor activity of folate conjugated chitosan coated EGCG nanoparticles. Food Sci. Biotechnol. 2014, 23, 569-575.

143. Singh, B.N.; Shankar, S.; Srivastava, R.K. Green tea catechin, epigallocatechin-3-gallate (EGCG): Mechanisms, perspectives and clinical applications. Biochem. Pharmacol. 2011, 82, 1807-1821.

144. Sanna, V.; Roggio, A.M.; Pala, N.; Marceddu, S.; Lubinu, G.; Mariani, A.; Sechi, M. Effect of chitosan concentration on PLGA microcapsules for controlled release and stability of resveratrol. Int. J. Biol. Macromol. 2015, 72, 531-536.

145. Alzheimer's Association. Alzheimer's disease facts and figures. Alzheimers Dement. 2012, 8, 131-168.

146. Bieschke, J. Natural compounds may open new routes to treatment of amyloid diseases. Neurotherapeutics 2013, 10, 429-439.

147. Kim, M.S.; Sung, M.J.; Seo, S.B.; Yoo, S.J.; Lim, W.K.; Kim, H.M. Water-soluble chitosan inhibits the production of pro-inflammatory cytokine in human astrocytoma cells activated by amyloid beta peptide and interleukin-1beta. Neurosci. Lett. 2002, 321, 105-109.

148. Wei, P.; Ma, P.; Xu, Q.S.; Bai, Q.H.; Gu, J.G.; Xi, H.; Du, Y.G.; Yu, C. Chitosan oligosaccharides suppress production of nitric oxide in lipopolysaccharide-induced N9 murine microglial cells in vitro. Glycoconjugate J. 2012, 29, 285-295.

149. Howlett, G.J.; Moore, K.J. Untangling the role of amyloid in atherosclerosis. Curr. Opin. Lipidol. 2006, 17, 541-547.

150. Herczenik, E.; Gebbink, M.F.B.G. Molecular and cellular aspects of protein misfolding and disease. FASEB J. 2008, 22, 2115-2133.

151. Korporaal, S.J.; Gorter, G.; van Rijn, H.J.; Akkerman, J.W. Effect of oxidation on the platelet-activating properties of low-density lipoprotein. Arterioscler. Thromb. Vasc. Biol. 2005, 25, 867-872.

152. Herczenik, E.; Bouma, B.; Korporaal, S.J.A.; Strangi, R.; Zeng, Q.; Gros, P.; van Eck, M.; van Berkel, T.J.C.; Gebbink, M.F.B.G.; Akkerman, J.W.N. Activation of Human Platelets by Misfolded Proteins. Arterioscler. Thromb. Vasc. Biol. 2007, 27, 1657-1665.

153. Ursini, F.; Davies, K.J.; Maiorino, M.; Parasassi, T.; Sevanian, A. Atherosclerosis: Another protein misfolding disease? Trends Mol. Med. 2002, 8, 370-374. 
154. Hayden, M.R.; Tyagi, S.C.; Kerklo, M.M.; Nicolls, M.R. Type 2 diabetes mellitus as a conformational disease. JOP 2005, 6, 287-302.

155. Stewart, C.R.; Tseng, A.A.; Mok, Y.F.; Staples, M.K.; Schiesser, C.H.; Lawrence, L.J.; Varghese, J.N.; Moore, K.J.; Howlett, G.J. Oxidation of low-density lipoproteins induces amyloid-like structures that are recognized by macrophages. Biochemistry 2005, 44, 9108-9116.

156. Kowalska, M.A.; Badellino, K. $\beta$-Amyloid protein induces platelet aggregation and supports platelet adhesion. Biochem Biophys. Res. Commun. 1994, 205, 1829-1835.

157. Laske, C.; Sopova, K.; Stellos, K. Platelet activation in alzheimer's disease: From pathophysiology to clinical value. Curr. Vasc. Pharmacol. 2012, 10, 626-630.

158. Ho, C.; Stubbs, C.D. Hydration at the membrane protein-lipid interface. Biophys. J. 1992, 63, 897-902.

159. Anraku, M.; Kabashima, M.; Namura, H.; Maruyama, T.; Otagiri, M.; Gebicki, J.M.; Furutani, N.; Tomida, H. Antioxidant protection of human serum albumin by chitosan. Int. J. Biol. Macromol. 2008, 43, 159-164.

160. Arakawa, T.; Prestrelski, S.J.; Kenney, W.C.; Carpenter, J.F. Factors affecting short-term and long-term stabilities of proteins. Adv. Drug Deliv. Rev. 1993, 10, 1-28.

161. Lahm, D.; Lee, L.K.; Bettelheim, F.A. Age dependence of freezable and nonfreezable water content of normal human lenses. Investig. Ophthalmol. Vis. Sci. 1985, 26, 1162-1165.

162. Kerch, G.; Rustichelli, F.; Ausili, P.; Zicans, J.; Merijs Meri, R.; Glonin, A. Effect of chitosan on physical and chemical processes during bread baking and staling. Eur. Food Res. Technol. 2008, 226, 1459-1464.

163. Kerch, G.; Zicans, J.; Merijs Meri, R.; Stunda-Ramava, A.; Jakobsons, E. The use of thermal analysis in assessing the effect of bound water content and substrate rigidity on prevention of platelet adhesion. J. Therm. Anal. Calorim. 2015,120, 533-539.

164. No, H.K.; Meyers, S.P.; Prinyawiwatkul, W.; Xu, Z. Applications of chitosan for improvement of quality and shelf life of foods: A review. J. Food Sci. 2007, 72, R87-R100.

165. Park, I.K.; Lee, Y.K.; Kim, M.J.; Kim, S.D. Effect of surface treatment with chitosan on shelf-life of baguette. J. Chitin Chitosan 2002, 7, 208-213.

166. Ahn, D.H.; Choi, J.S.; Lee, H.Y.; Kim, J.Y.; Youn, S.K.; Park, S.M. Effects on preservation and quality of bread with coating high molecular weight chitosan. Korean J. Food Nutr. 2003, 16, 430-436.

167. Park, I.K.; Lee, Y.K.; Kim, M.J.; Kim, S.D. Effect of surface treatment with chito-oligosaccharide on shelf-life of baguette. J. Chitin Chitosan 2002, 7, 214-218.

168. Lee, H.Y.; Kim, S.M.; Kim, J.Y.; Youn, S.K.; Choi, J.S.; Park, S.M.; Ahn, D.H. Effect of addition of chitosan on improvement for shelf-life of bread. J. Korean Soc. Food Sci. Nutr. 2002, $31,445-450$.

169. Lee, K.H.; Lee, Y.C. Effect of carboxymethyl chitosan on quality of fermented pan bread. Korean J. Food Sci. Technol. 1997, 29, 96-100.

170. Kerch, G.; Zicans, J.; Merijs Meri, R. The effect of chitosan oligosaccharides on bread staling. J. Cereal Sci. 2010, 52, 491-495.

171. Knorr, D. Functional properties of chitin and chitosan. J. Food Sci. 1982, 47, 593-595. 
172. Lafarga, T.; Gallagher, E.; Walsh, D.; Valverde, J.; Hayes, M. Chitosan-containing bread made using marine shellfishery byproducts: Functional, bioactive, and quality assessment of the end product. J. Agric. Food Chem. 2013, 61, 8790-8796.

173. Fadda, C.; Sanguinetti, A.M.; Del Caro, A.; Collar, C.; Piga, A. Bread staling: updating the view. Compr. Rev. Food Sci. Food Saf. 2014, 13, 473-492.

174. Lafarga, T.; Hayes, M.; Valverde, J.; Walsh, D.; Gallagher, E. Prawn chitosan containing bread: assessment of functional, bioactive and sensory qualities. J. Chitin Chitosan Sci. 2013, 1, $150-156$.

175. Kerch, G.; Glonin, A.; Zicans, J.; Merijs Meri, R. A DSC study of the effect of ascorbic acid on bound water content and distribution in chitosan-enriched bread rolls during storage. J. Therm. Anal. Calorim. 2012, 108, 73-78.

176. Rakcejeva, T.; Rusa, K.; Dukalska, L.; Kerch, G. Effect of chitosan and chitooligosaccharide lactate on free lipids and reducing sugars content and on wheat bread firming. Eur. Food Res. Technol. 2011, 232, 123-128.

177. Kerch, G.; Glonin, A.; Zicans, J.; Merijs Meri, R. A DSC study of the effect of bread making methods on bound water content and redistribution in chitosan enriched bread. J. Therm. Anal. Calorim. 2012, 108, 185-189.

178. Lee, J.W.; Lee, Y.C. The physico-chemical and sensory properties of milk with water soluble chitosan. Korean J. Food Sci. Technol. 2000, 32, 806-813.

179. El-Sisi, A.S. Impact of replacement of gelatin with chitosan on the physicochemical properties of ice-milk. Int. J. Dairy Sci. 2015, 10, 26-33.

180. Kwak, H.S.; Mijan, M.A.; Ganesan, P. Application of Nanomaterials, Nano- and Microencapsulation to Milk and Dairy Products, in Nano- and Microencapsulation for Foods; Kwak, H.-S., Ed.; John Wiley \& Sons, Ltd: Chichester, UK, 2014; doi:10.1002/9781118292327.ch11.

181. Zanjani, M.A.K.; Mohammadi, N.; Ahari, H.; Tarzi, B.G.; Bakhoda, H. Effect of microencapsulation with chitosan coating on survival of Lactobacillus casei and Bifidobacterium bifidum in ice cream. Iran. J. Nutr. Sci. Food. Technol. 2014, 8, 125-134.

182. Eduardo, M.F.; Correa De Mello, K.G.P.; Polakiewicz, B.; Da Silva Lannes, S.C. Evaluation of chocolate milk beverage formulated with modified chitosan. J. Agric. Sci. Technol. 2014, 16, 1301-1312.

183. Tasneem, M.; Siddique, F.; Ahmad, A.; Farooq, U. Stabilizers: Indispensable substances in dairy products of high rheology. Crit. Rev. Food Sci. Nutr. 2014, 54, 869-879.

184. Zagorska, J.; Pelnik, A.; Kerch, G. Effect of the addition of chitosans with different molecular structure on fermentation process and viscosity changes during sour cream storage. Biochem. Biophys. (BAB) 2013, 1, 13-21.

185. Rajapaksha, D.S.W.; Kodithuwakku, K.A.H.T. Evaluation of chitosan for its inhibitory activity on post-acidification of set yoghurt under cold storage for 20 days. J. Chitin Chitosan 2014, 2 , $16-20$.

186. Seo, M.H.; Chang, Y.H.; Lee, S.; Kwak, H.S. The physicochemical and sensory properties of milk supplemented with ascorbic acid-soluble nano-chitosan during storage. Int. J. Dairy Technol. 2011, 64, 57-63. 
187. Choi, H.J.; Ahn, J.; Kim, N.C.; Kwak, H.S. The Effects of Microencapsulated chitooligosaccharide on physical and sensory properties of the milk. Asian Aust. J. Anim. Sci. 2006, 19, 1347-1353.

188. Krasaekoopt, W.; Bhandari, B.; Deeth, H.C. Survival of probiotics encapsulated in chitosan-coated alginate beads in yoghurt from UHT-and conventionally treated milk during storage. LWT-Food Sci. Technol. 2006, 39, 177-183.

189. Seo, M.H.; Lee, S.Y.; Chang, Y.H.; Kwak, H.S. Physicochemical, microbial, and sensory properties of yogurt supplemented with nanopowdered chitosan during storage. J. Dairy Sci. 2009, 92, 5907-5916.

190. Altieri, C.; Scrocco, C.; Sinigaglia, M.; del Nobile, M.A. Use of chitosan to prolong mozzarella cheese shelf life. J. Dairy Sci. 2005, 88, 2683-2688.

(C) 2015 by the authors; licensee MDPI, Basel, Switzerland. This article is an open access article distributed under the terms and conditions of the Creative Commons Attribution license (http://creativecommons.org/licenses/by/4.0/). 